\title{
Advanced Smart Material Based Nano sensors for Viral Detections *
}

\author{
Muhammad Umara ${ }^{\mathrm{a}}$, Hifza Nawaz ${ }^{\mathrm{a}}$, Iqra Nawaz ${ }^{\mathrm{b}}$, Yi Li ${ }^{\mathrm{a}, *}$ \\ ${ }^{a}$ Department of Materials, University of Manchester, Oxford Road, Manchester, M13 9PL, UK \\ ${ }^{\mathrm{b}}$ Nuclear Institute for Agriculture and Biology, Jhang Rd, Faisalabad, 38000, Pakistan
}

\begin{abstract}
Now-a-days, researchers focus on the use of smart materials due to their multiple functional capabilities. A "smart material" is one having a nano level structure that can responds in a specialised and controlled way to influence on its sensing mechanisms. Due to the multiple properties of smart materials, they have a great influence on current analytical methods and diagnostic strategies by reorganizing the sensing modules for nano-sized objects (protein biomarkers and viruses) and biomolecules detection. Incontestably, current sensing mechanisms need a continuous update for addressing the growing challenges in the field of diagnosis for viruses because these viruses altered and spread rapidly from person-topersons. It becomes critical to take into consideration several factors for viral diagnosis ranging from the type and quality of specimen collected, mode of transport, time of specimen collection, level of accuracy or specificity, viral detection sensitivity, and the type of diagnostic method used. In this review, we briefly explained the principle and different types of smart materials being used for diagnosing infectious viruses. The development in the field of smart material based nano sensors with resource-scarce settings is further discussed and elaborated the pros and cons of current methods for viral detection as a conclusion and future perspective.
\end{abstract}

Keywords: Viruses; Smart Materials; Nanosensors; Graphene; Sensing Mechanism

\section{Introduction}

Smart materials has the capability to work in an intelligent and sustainable direction by combining all its services into a cohesive unit and employing clever devices to control and monitor the viral infections [1]. Nowadays, thousands of people suffer from several diseases due to numerous medical problems [2]. Most of them are related to the infectious diseases that not only

${ }^{\star}$ Project supported by the EU Horizon 2020 and University of Manchester through projects with project codes 644268 - ETEXWELD - H2020-MSCA-RISE-2014, AA14512 (UMRI project "Graphene-Smart Textiles EHealthcare Network") and R119938 ('Protective Efficiency of Respiratory Protective Equipment (RPE) against Byssinosis for Cotton Workers')

${ }^{*}$ Corresponding author.

Email address: henry.yili@manchester.ac.uk (Yi Li). 
affect humans lives but also danger for animals and plants lives [3]. These diseases (human immunodeficiency virus (HIV), malaria, and tuberculosis) mostly affect the people of undeveloped countries [4]. Viruses contaminating the sources is one of the main reasons of spread of diseases in these countries which not only causes suffering among the people but also lead to deaths of hundreds and thousands of people each year. Viruses are the type of parasites that require the host cell for generation and replication process. Complex protection mechanisms have been developed by mammalian cells to detect and hinder viral replication. In response, viruses can break down and control the host immune reactions. This has allowed the growth of viruses that are proficient at destroying host immune reactions [5]. The early determination of pathogenic agents like bacteria and viruses is crucial for clinical point-of-care purposes [6]. Polymerase chain reaction [7], enzyme-linked immunosorbent assay, reverse transcription polymerase chain reaction [8], and different smart material based nano sensor technologies are being used to detect or treat them [9]. A smart material based nano sensor basically contain three type of modules: a detector, a receptor, and a transducer which give digital output. Firstly targeted molecules attach with the receptor sites where biological molecules are detected through a reaction that take place on biologically detecting component [10]. Then transducers are used to convert these changes into the signal which are quantified with the help of the detector [11]. Nanosensors are built from such type of smart material which have multiple properties of exceptional performance, high specificity, practicable operation, excellent sensitivity, fast response, portability and condensed size with real-time analysis [12]. Nowadays, mostly investigators give preference to the methods which improve the specificity and sensitivity through focusing on the smart material based nanosensor production. It also improves the quality and increases affinity between the surfaces by employing nanocomposites such as quantum dots [13] and gold nanoparticles [14] for signal amplification studies. From the previous decades, smart material based nanosensors have revolved due to detection of distinctive type of analytes such as cancer biomarkers [15], explosives [16], nucleic acids [17], proteins [18], bacteria [19] viruses [20], and toxins during food processing [21], environmental monitoring [22] and clinical diagnostics.

There are various kind of smart material based nanosensors that have different principles of viral detection. Electrochemical nanosensors including screen-printed electrodes and semiconductors can monitor changes in dimension, charge distribution, dielectric properties and shape, while the complex charge is produced on the electrode. Electrochemical nanosensors are divided into three different groups, amperometric, impedimetric, and potentiometric transducers, and all of them are utilized to detect targeted viruses [23]. Optic nanosensors measure the change of the reflective index of the transducer when the target and recognition element produces a complex [24]. They have a multipurpose detection scale and can sense various kinds of biomolecules from different specimens [25]. Piezoelectric type of nanosensors can measure change in mass and viscoelasticity through modified quartz crystal resonator and recorded frequencies. Such kind of sensing require isolation equipment which can minimize hindrance effects to achieve high sensitivity for different environmental conditions. These smart materials based nanosensors have been used in a wide variety of applications to identify targeted viruses. Thermal nanosensors are based on the principle of heat absorption or evolution to exploit the basic properties of biological reactions [26]. Magnetic smart material based nanosensors carry out the magnetic beads which were coated with a ligand, so they have ability to be detect viruses through magnetic field [27].

In this review, we will briefly explain the principle and different types of smart material based 
Table 1: Common detection techniques and their principles for viral detection

\begin{tabular}{|c|c|c|c|c|c|}
\hline $\begin{array}{l}\text { Detection } \\
\text { Technique }\end{array}$ & Advantages & $\begin{array}{l}\text { Working } \\
\text { Principle }\end{array}$ & $\begin{array}{l}\text { Duration } \\
\text { Time }\end{array}$ & Disadvantages & Ref. \\
\hline Cell culture & $\begin{array}{l}\text { 1. Inexpensive } \\
\text { 2. Broad spectrum }\end{array}$ & $\begin{array}{l}\text { Infectivity as- } \\
\text { say }\end{array}$ & $\begin{array}{l}\text { Days to } \\
\text { weeks }\end{array}$ & $\begin{array}{l}\text { Difficulty in maintaining cell cul- } \\
\text { tures; Contamination problems. }\end{array}$ & {$[27]$} \\
\hline $\begin{array}{l}\text { Hemagglutination } \\
\text { assay }\end{array}$ & $\begin{array}{l}\text { 1. Easy to handle } \\
\text { 2. Inexpensive }\end{array}$ & Viral protein & Hours & $\begin{array}{l}\text { Poor sensitivity; necessity for } \\
\text { fresh reagents }\end{array}$ & {$[28]$} \\
\hline ELISA & $\begin{array}{l}\text { 1. Single incubation } \\
\text { step } \\
\text { 2. No hook effect at } \\
\text { high analyte concen- } \\
\text { trations }\end{array}$ & Viral protein & Hours & $\begin{array}{l}\text { Limited concentration range in } \\
\text { which the analyte can be quanti- } \\
\text { fied without sample dilution; and } \\
\text { that the antigen or antibody pro- } \\
\text { duce the same response and not } \\
\text { distinguishable in a one step }\end{array}$ & {$[29]$} \\
\hline $\begin{array}{l}\text { Electron } \\
\text { microscopy }\end{array}$ & $\begin{array}{l}\text { 1. Broad spectrum } \\
\text { 2. Fast method }\end{array}$ & Viral particle & Hours & $\begin{array}{l}\text { Necessity for presence of around } \\
10^{6} \text { virus particles } / \mathrm{mL} \text { for detec- } \\
\text { tion; similarity of morphologies }\end{array}$ & {$[30]$} \\
\hline PCR & $\begin{array}{l}\text { 1. Excellent sensitivity } \\
\text { 2. Easy to handle }\end{array}$ & $\begin{array}{l}\text { Viral nucleic } \\
\text { acid }\end{array}$ & Hours & $\begin{array}{l}\text { Extremely liable to contamina- } \\
\text { tion; Not easy to quantitate re- } \\
\text { sults; High degree of operator } \\
\text { skill required }\end{array}$ & {$[31]$} \\
\hline
\end{tabular}

nanosensors. We will also give an overview on new nanosensors and technologies which are extensively discussed according to the latest research findings for rapid assessment of the medical applications to diagnose infectious diseases. Finally, conclusion and future perspectives are mentioned to compare commercial biosensors and sum up the review.

\section{Importance of Virus Detection}

Nowadays, Infectious diseases have a great threat to health, not only in rural areas but also in big cities. Underlying cases for such serious maladies can be summarized as the lack of available analysis methods and subsequent treatment strategies due to the limited access of centralized and equipped health-care facilities [32]. Many researchers, such as physicists, chemists, biologists, and medical doctors, have used nanosensors as applications in several fields, including doping analysis, diagnosis, food safety, and laboratory medicine. Among them, clinical applications have been researched as an impressive field of application. Due to the necessity to enhance detecting properties and rapid analysis, new recognition molecules are being examined. The detection performance of the nanosensors can be improved by using different combinations of smart materials. These properties make them suitable for clinical applications that can do rapid and multimolecule detection. 


\section{Applications of Smart Material Based Nanosensors for Viral Detection}

\subsection{Hepatitis B Virus}

Hepatitis virus has been known from 1940's and causing transient and chronic hepatitis [33]. Hepatitis B virus (HBV) is one of the main infections evaluated to cause almost a million deaths every year due to cirrhosis and malignant liver growth. In addition, 15\%-40\% of infected patients have reported liver failure, liver cirrhosis, or hepatocellular carcinoma, and unfortunately about $15 \%-25 \%$ died [34].

Hassen et al. reported a study on the DNA hybridization for the detection of the HB virus through the electrochemical impedance spectroscopy. Firstly, they changed probes of DNA through the magnetic nanoparticles and then these were immobilized into the gold platted electrode. Following the characterizations, they showed a good DNA immobilization and hybridization with different concentrations of complementary DNA. Moreover, they exhibited that this nanosensor has detected pmol of HBV DNA, and saturation reached $12.65 \mathrm{nM}$ [35]. Uzun et al. also reported HBV detection through the surface antibody taken from human serum by using optic nanosensor. They focused on the kinetic studies for employing the HBV surface antibody by using the samples of human serum. They proved that this nanosensor obeyed the principle of Langmuir adsorption isotherm [36]. Istek et al. worked on an electrochemical nanosensor to detect the selective sequencing of DNA hybridization that related to HBV detection. They performed the selectivity of the nanosensor in the presence of target and the other DNA sequences. They can calculate the detection value of $0.86 \mu \mathrm{g} / \mathrm{mL}$. A Chowdhury et al. developed a pulse triggered ultra-sensitive electrochemical sensor by using graphene quantum dots and gold-embedded polyaniline nanowires via interfacial polymerization and self-assembly approach. The sensitivity for HEV virus increased due to introduction of electric pulse during virus accumulation step which helps in expanding the surface of virus particle and antibody-conjugated polyaniline chain length, compared to other conventional electrochemical sensors. The sensor was used to test various genotypes of HEV collected from cell culture supernatant and fecal specimen obtained from HEV infected monkey. The sensitivity of developed sensor was found to be same as of real-time quantitative reverse transcription polymerase chain (RT-qPCR). The results obtained from this study suggest that the developed sensor can be used to develop a robust and high performance sensors for HEV detection [37]. C. Zhang et al., synthesised a sensitive, low-cost and convenient Quantum dots-based biosensor for the detection of HBV gene mutations in real human serum samples taken from chronic hepatitis B (CHB) patients. To evaluate the efficiency of detection, they compared their results with direct sequencing PCR method. In CHB, they used the fluorescent dyes to visualize the probes which contain the M204I Ms mutation, where the intensity of fluorescence is depended on the virus load. At present, the limits of the method used to detect HBV genetic variations by fluorescence quantum dots is 103 $\mathrm{IU} / \mathrm{ml}$. These results showed Quantum dots (QDs) are excellent semiconductor nanoparticles with a diameter of less than $10 \mathrm{~nm}$. The fluorescent probes used in biochemical analysis and vivo imaging because of their excellent optical properties such as high luminous brightness and strong light stability. The developed biosensors are low in cost, high throughput, high sensitivity and accuracy [38]. Figure 1 show QDs modified DNA probe for detecting Hepatitis B virus. 


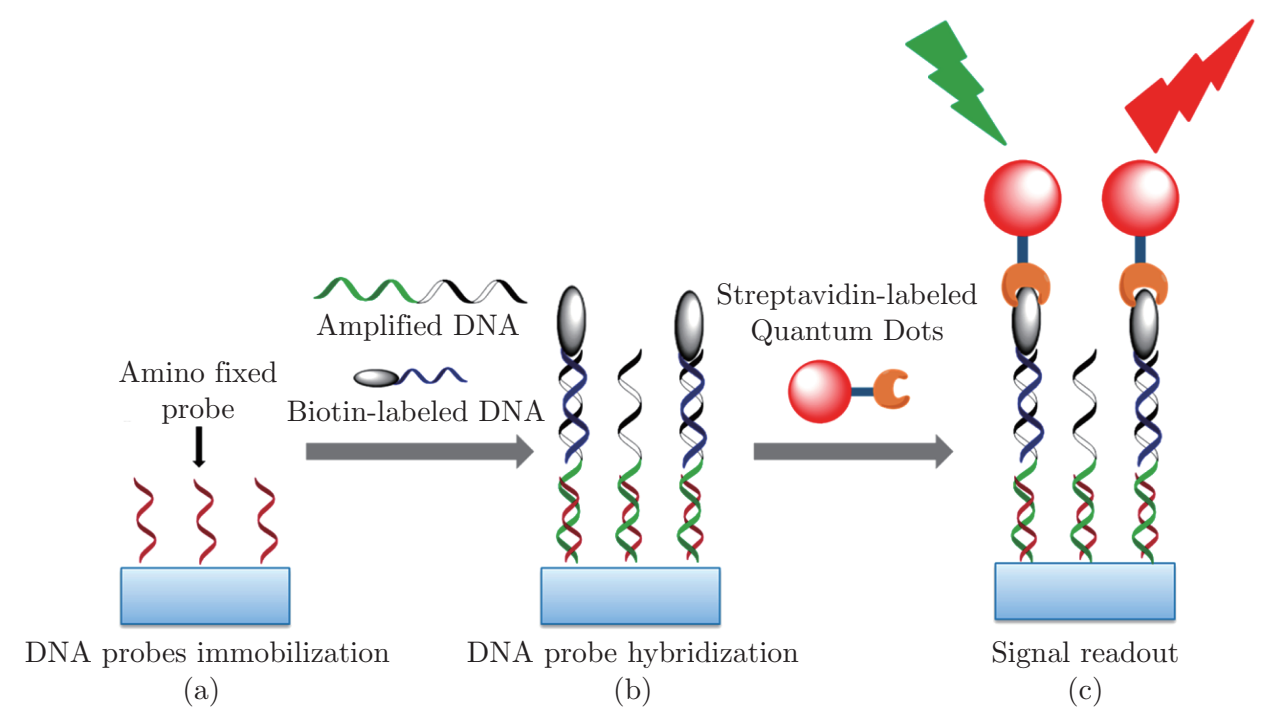

Fig. 1: QDs modified DNA probe for detecting Hepatitis B virus [38]

\subsection{Human Papillomavirus}

Human papillomavirus (HPV) was studied during the development in cervical cancer, which is the second-most prevalent form of malignancy among women. Early diagnosis lets patients to be taken care of at an early stage. Even at the condition of binary positive and negative indications, there is need of extreme utility of clinical diagnostics. For screening purpose, pap smear was used to detect the disease but due to less sensitivity and specificity, this method is not too effective [39].

Inan et al. formed a microfluidic based nanosensor for detection of HPV-16 E7 antibodies. The detection limit is about $2.87 \mathrm{ng} / \mathrm{mL}$. They describe it as valid nanosensor for serum-based samples and these supplied high responses in comparison to the control samples. It is also mentioned that such nanosensor can be used in form of pretesting tool for diagnosis of HPV related cancers [40]. Teengam et al. also reported a colorimetric based nanosensor for screening the synthetic HPV. For this purpose, firstly they developed a paper-based nanosensor that can detect DNA multiplex. The results were concluded through determination of the color change due to the presence of silver nanoparticles and their detection limit was found to be $1.03 \mathrm{nM}$. These nanosensors showed good selectivity for their complementary oligonucleotides over single-base mismatch, two-base mismatch, and noncomplementary targets of DNA molecule [41]. Peng et al. synthesized a nanosensor based on two-dimensional nanosheets for viral detection. These nanosheets were acquired by exfoliating their layered etched powder and exhibited high fluorescence quenching ability to dye-labeled single-stranded DNA and different affinities for single-stranded and doublestranded DNA. They observed that the single-stranded DNA probe showed minimal fluorescent emission under the fluorescence quenching effect of nanosheets. This nanosensor for HPV-18 detections showed high specificity and a low detection limit of 100 pM [42].

\subsection{Ebola Virus}

Ebola virus generate some severe infections that caused illness in humans after the period of incubation. Firstly, patients were generally suffered from the influenzas before a progressive dis- 
ease. These were characterized through shock-like syndrome, failures of organ, and haemorrhage. Due to Ebola virus infection one of the largest outbreak as discussed in Ref. [43]. Such advanced smart material based nanosensors would be perfect and fast for the detection of Ebola virus [44]. Natesan et al. reported a digital nanosensor for the detection of Ebola virus. Such nanosensor contain a flow cell-based assay that can detect the specific antibodies through micro arrayed recombinant antigens and a smartphone fluorescent reader. The readers of smartphone utilized their high-performance results clarification that has a hardware attachment to snap their interface for operational handling, these nanosensors can communicate with their cloud services and acquire test results. They also tested these nanosensor results with sera from nonhuman primates that received a live attenuated Ebola vaccine [45]. Ilkhani et al. reported an electrochemical based nanosensor for the identification of Ebola virus. Firstly, they marked their alkaline phosphatase conjugate (streptavidin) to optimize all the steps and received the detection of low limit value. Then they accomplished their selectivity as well as reproducibility. Yanik et al. synthesized the optical fluidic based nanosensor that can detect various type of viruses. These nanosensors rely on a principle of light transmission impact and used the specific group antibodies. These were applied in a range of spanning three orders magnitude. They also modify antibodies against the Ebola glycoprotein on the nanosensors, and collected transmission spectra after cleaning [46]. Y. Chen et al., developed a reduced graphene oxide based field-effect transistor method for real-time detection of the Ebola virus antigen. This method uses the attractive semiconductor characteristics of graphene-based material, and instantaneously yields sensor for highly sensitive and specific detection of Ebola glycoprotein. The feasibility of this method for clinical application in point-of-care technology is evaluated using Ebola glycoprotein suspended in diluted PBS buffer, human serum, and plasma. These results demonstrate the successful fabrication of a promising field-effect transistor biosensor for EVD diagnosis. Figure 2 illustrates the detection of Ebola virus using field effect transistor biosensor [47].

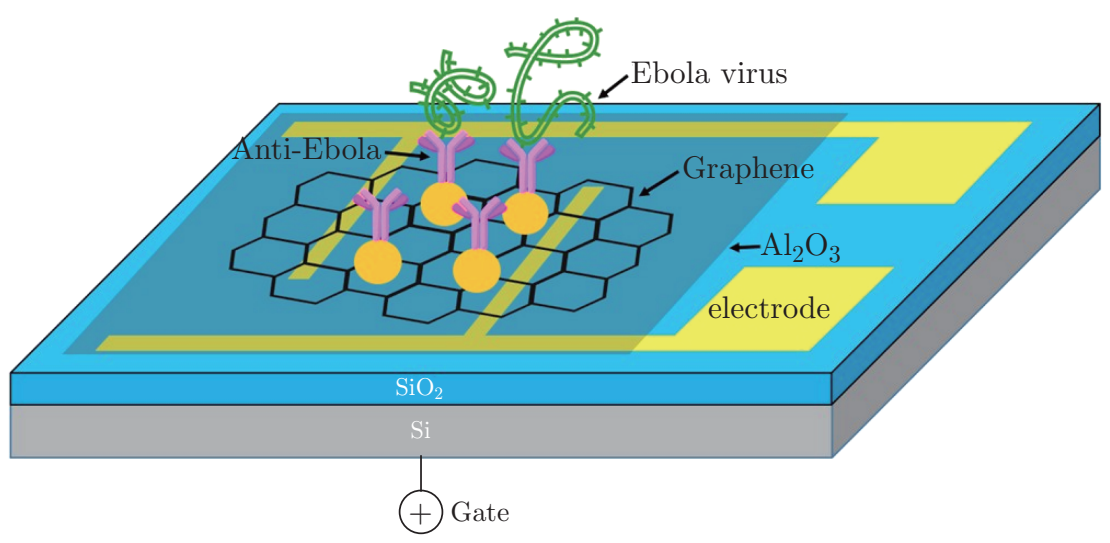

Fig. 2: Field-Effect Transistor Biosensor for Rapid Detection of Ebola [47]

\subsection{Zika Virus}

Zika virus is a type of mosquito-borne virus. Before 2007, Asian and African people were mostly affected by this virus. Its first case was reported in the Federated States of Micronesia [48]. Emerging infectious illnesses, such as the Zika virus epidemic spanning the Western Hemisphere, have demanded renewed studies regarding the requirement to produce simplified diagnostic tests. Zika is a vector borne viral infection originated in the Zika Forest of Uganda in the mid-20th 
century. Over 41, 000 cases of Zika virus infection have been reported since January 2015. Among these, about 3461 cases were reported in pregnant women (Center for Disease Control, 2017). It also cause severe brain defects in fetuses [49].

Afsahi et al. reported a graphene-based nanosensor for Zika virus detection. They can quantify very low number of viral antigens of Zika infection (450 pM). Graphene-based potential diagnostic nanosensor can also detect the Zika antigen from human serum. Then it was also validated on the base of the selectivity with Japanese company NS1 [50]. Kaushik et al. developed an electrochemical based nanosensor for (Zika) viral detection. For this purpose, they used electrochemical impedance spectroscopy for the response measurement and result showed that nanosensor has the ability to detection of Zika virus within a range of $10 \mathrm{pM}-1 \mathrm{nM}$ [51]. Song et al. reported a study that based on the principle of reverse-transcription loop-mediated isothermal amplification for Zika virus detection. They used the real samples to exhibit the application of this nanosensor in the detection of Zika virus with 5 pfu sensitivity [52].

S. Afsahi et al. also produced a cost-effective graphene-based biosensor to detect Zika viruses. The developed sensor is portable and has high specific immobilized antibody. The monoclonal antibodies were covalently bonded with graphene for early detection of zika viral antigens. The change in doses of zika virus antigen was detected as change in capacitance as response which is in accordance with detection of antigen in buffer at concentrations as low as $450 \mathrm{pM}$ in clinical area. The zika antigen was also measured in simulated human serum to demonstrated potential diagnostic applications. The graphene-based sensor developed to detect zika viruses has the ability to be used in clinical research as well as diagnostic application due to its selectivity, rapidness and high sensitivity [50].

S, Afsahi developed a cost-effective and portable graphene-enabled biosensor to detect Zika virus with a highly specific immobilized monoclonal antibody. Figure 3 illustrates graphene-based biosensor for detection of coronavirus. Field Effect Biosensing (FEB) with monoclonal antibodies covalently linked to graphene enables real-time, quantitative detection of native Zika viral (ZIKV) antigens. Potential diagnostic applications were demonstrated by measuring Zika antigen in a simulated human serum. Further, the graphene platform, is a single layer, two-dimensional sheet of hexagonally arranged carbon atoms which has high electronic conductivity, high carrier mobility, and large surface area. As a conductive, two-dimensional material, every atom in a graphene sheet is in direct contact with its environment and responds to electrostatic fluctuations, making it an ideal candidate for sensing application. Graphene-based FET biosensors can detect surrounding changes on their surface. They provide an optimal sensing environment for ultrasensitive and low-noise detection [50].

\subsection{Influenza Virus}

Influenza is a viral infection and cause serious clinical issues and a lot of economic interruptions. The common methods for Influenza virus detection are difficult to handle and time-consuming. Three pandemics has been occured within the 20th century. In 2009, Pandemic influenza A (H1N1) \& (pH1N1) emerged and circulated globally and approximately 100 million people were died worldwide. Every year about 1 billion people suffer from new infections. Still 250, 000 deaths occur all over the world every year. So it is important for the researchers to develop effective conventional methods [53].

Tam et al. reported a research article about the DNA immobilization through employing car- 

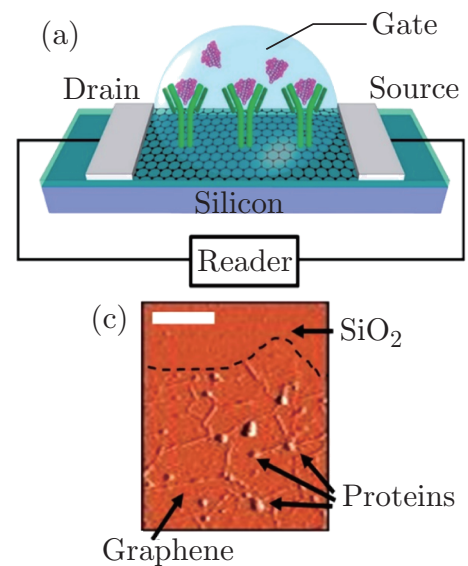

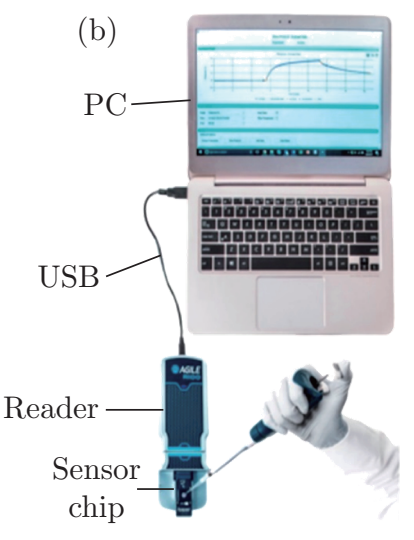

Fig. 3: Graphene based biosensor for detecting Zika virus [50]

bon nanotubes on the surface of nanosensor for the detection of influenza virus. Firstly, they developed a modified DNA probe onto the surface of nanosensor, then characterized it with the fundamental interactions. The detection limit of nanosensor was about $0.5 \mathrm{nM}$ that targeted DNA probe on hybridization [54]. Vollmer et al. reported a nanosensor that based on the principle of optical method for influenza virus detection. They focused on the single version of binding experiments that changes the frequency resonance through a whispering-gallery mode. They also used nanoparticles in the sensing mechanism that depend on the size of virus [55]. Bai et al. synthesised a portable nanosensor based on optical method. They were employing an aptamer for the detection of avian influenza virus (AIV) H5N1. The aptamers were immobilized when it captured the AIV H5N1 which cause a change in the refraction index. Following the optimization of experimental parameters, their results displayed that the refraction index value was linearly associated with AIV concentration [56]. Emir Diltemiz et al. developed the nanosensors that based on the piezoelectric and optical method for the hemagglutinin detection which was main protein of this virus. To indicate sialic acid, they used 4-aminophenylboronic acid. For surface modification of the nanosensor surfaces, thiol groups were attached to immobilized 4-aminophenylboronic acid and sialic acid. Calculated detection limit was about $4.7 \times 10^{-2}$ and $1.28 \times 10^{-1} \mu \mathrm{m}$ for piezoelectric and optic nanosensors respectively.

D. Su et al. manufactured a wash free magnetic bioassay integrated with Z-lab handheld system based on giant-magnetoresistance (GMR) sensors. It can be used for IAV detection of nasal swab samples and the detection process was simplified and accelerated due to the wash free magnetic bioassay. This new sensing procedure simplifies the testing due to mixing antibodies, antigens and magnetic nanoparticles at same time in the bio-functionalization process and without repeated washings and very low losses in efficiency. This new procedure can successfully detect IAV nucleoprotein (as low as $0.3 \mathrm{nM}$ ) and IAV-contained nasal swab samples. An efficient point of care device was developed which can be used to detect biomarkers in complex sample matrix [57].

K. Siuzdak et al., developed a boron-doped diamond-based biosensor for the direct detection of the viral particles at ultralow concentrations. Polyclonal antibodies M1 against the M1 protein, the universal biomarker of influenza virus, are attached to the surface of diamond electrode. Capturing the M1 protein results in electrochemical impedance spectra changes. The achieved limit of detection (LOD) for the approach using M1 biomarker in saliva buffer is $5 \times 10-14 \mathrm{~g} / \mathrm{mL}$, i.e., several virus particles per sample. Additionally, this assay may be developed into the first 
commercial biosensor with wide potential window. It shows high stability, low background current, biocompatibility, and chemical inertness. The combination also results in high sensitivity and specificity with fast response, low electrical noise and background level. Diamond based platforms also provides high flexibility and affinity [58]. Figure 4 illustrates biomolecular detection of influenza virus by electrochemical impedance spectroscopy.

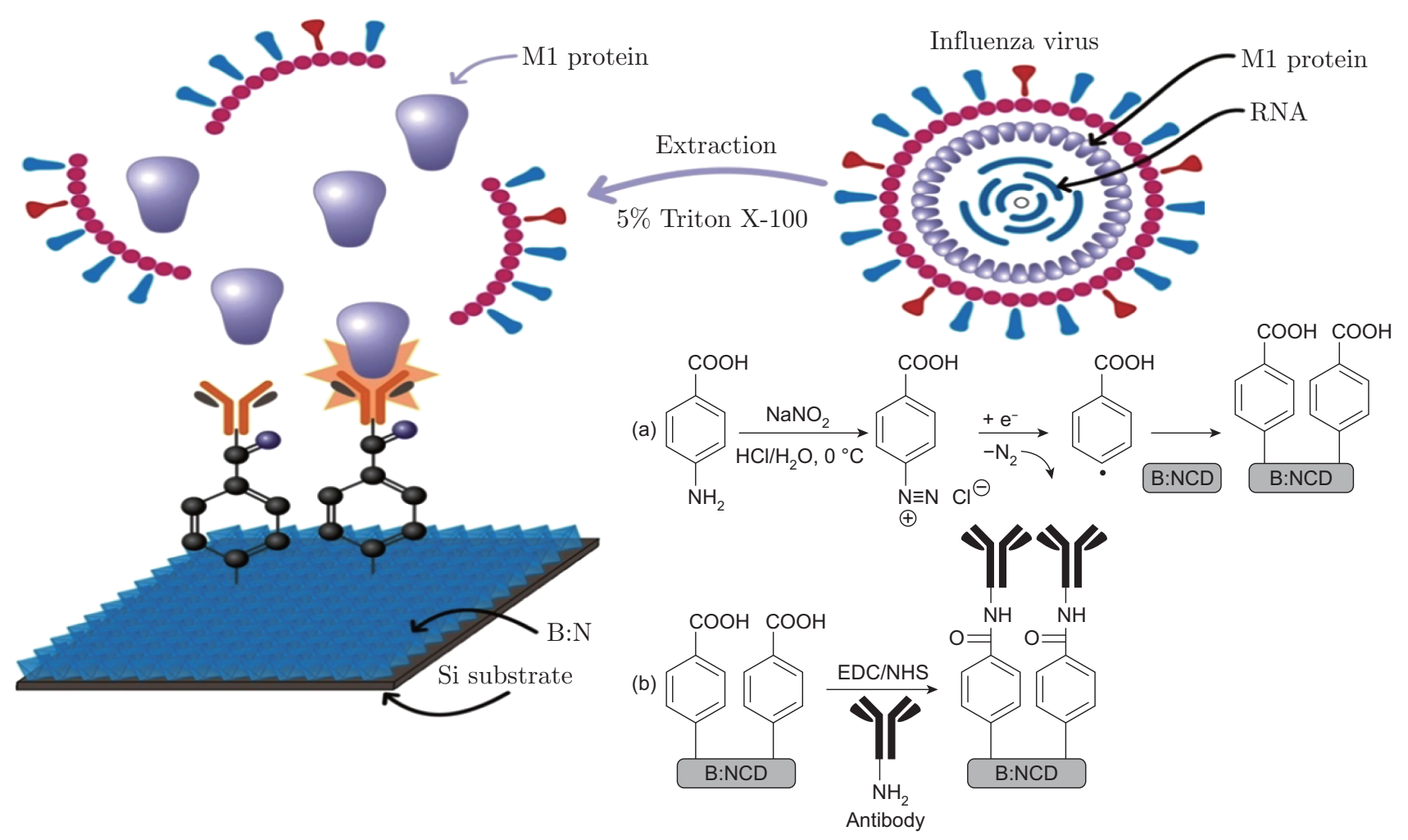

Fig. 4: Biomolecular influenza virus detection by the electrochemical impedance spectroscopy [58]

S. Joshi et al. developed a label free electrochemical immunosensor for quantitative detection of influenza virus via electrochemical impedance spectroscopy. Firstly, thermal treatment was used to obtain a biocompatible, low cost and scalable reduced graphene oxide from shellac. The rGO flakes with high carbon percentage, crystallinity and low sheet resistance were deposited and drop cast on indium tin oxide/glass electrodes to manufacture a label free electrochemical immuno biosensor. These rGO based sensors are cost effective and possess high stability and reproducibility. The limits of detection (LOD) for the target virus in PBS and saliva samples were estimated to be 26 and $33 \mathrm{PFU} / \mathrm{ml}$, respectively. The developed sensor exhibit potential to develop a wide variety of robust and reliable immunosensors and nanomaterial based biosensors for various medical applications [59].

W. Hai et al. developed a highly sensitive trisaccharide grafted conducting polymers for label free detection of influenza virus with great specificity. The trisaccharides composed of sialyllactose were covalently attached to side chain of conducting polymers as a ligand for detection of viruses. Quartz crystal microbalance (QCM) and contact angle readings were taken to confirm the immobilization of sialyllactose. The interaction of the sialyllactose with hemagglutinin was determined in presence of influenza virus by QCM and potentiometry which shows higher sensitivity than commercially available kits. The easy processability and mass production makes novel conducting polymers with specific detection abilities an ideal materials for point of care 


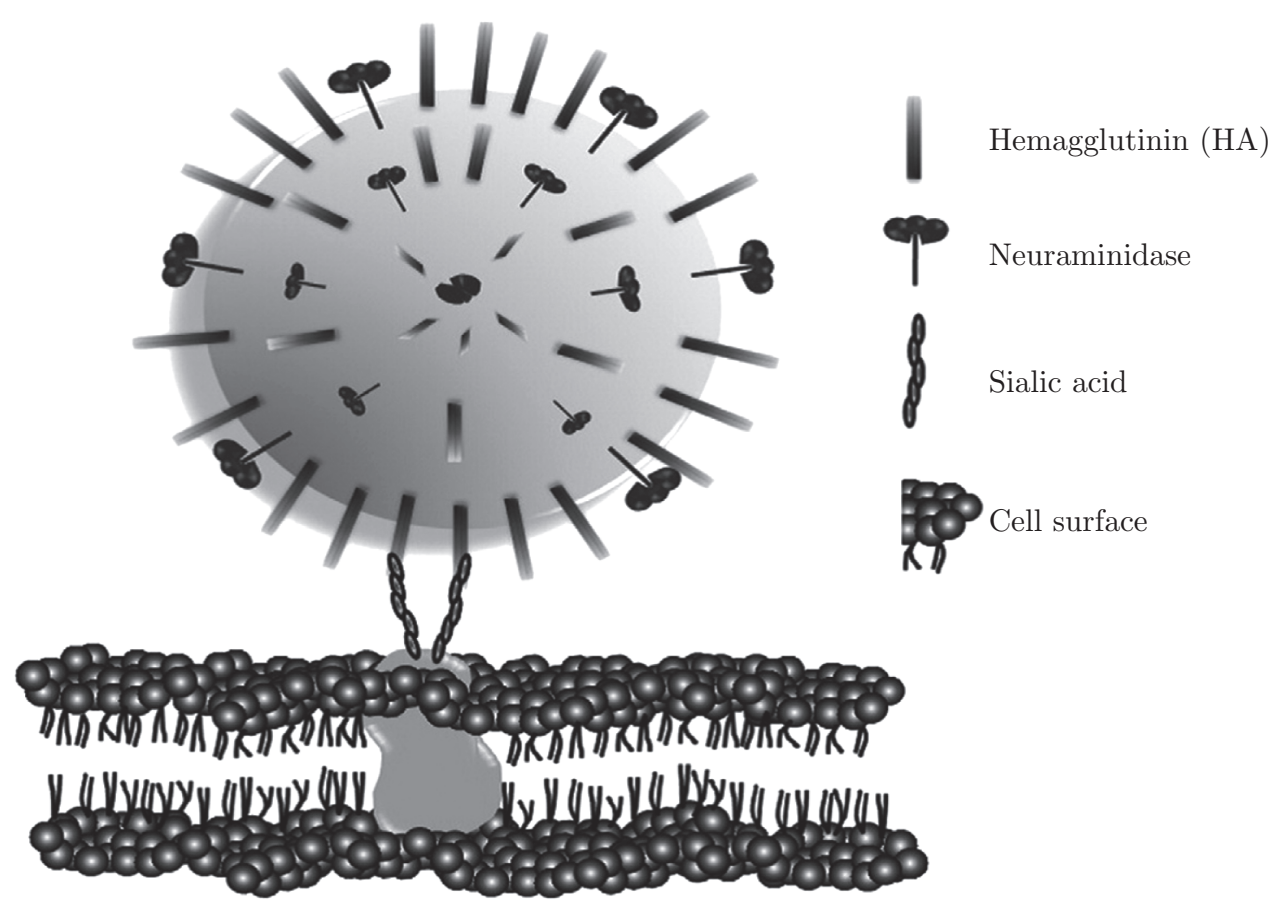

Fig. 5: Schematic representation of binding of influenza [60]

and wearable devices [60].

\subsection{Norovirus}

Norovirus is a type of pathogen that can directly enter the human and causes severe diseases. Norovirus is an important reason for morbidity because of acute gastroenteritis both inside health care institutions and in the more extensive network. Norovirus can easily spread through fecal or oral ways contamination that mostly happen due to the contaminated water or food, and infection from one person to another person [61]. The most important reason for acute gastroenteritis outbreaks and sporadic disease was identified as Noroviruses worldwide [62]. Numerous examinations have concentrated on giving promising alternative techniques to detect noroviruses in more sensitive and accurate ways like aptamer-based electrochemical biosensors and microfluidic chips.

Exemplarily, Ashiba et al. investigated a surface plasmon resonance biosensor to detect norovirus like particles. The biosensor was designed by using a chip that equipped with a V-shaped trench. They selected a wavelength of $390 \mathrm{~nm}$ for the excitation of the surface plasmon resonance on the aluminum film. $0.01 \mathrm{ng} / \mathrm{mL}$ concentration was easily detectable by this sensor that corresponds to 100 virus-like particles included in the detection region of the V-trench [63]. M. Richter et al., designed an optical fibre-based biosensor for the detection of norovirus virus-like particles (VLPs). The sensor is based on highly sensitive long period fibre gratings (LPFGs) coated with antibodies against the main coat protein of the norovirus. Several modification methods were verified to obtain reliable immobilization of protein receptors on the LPFG surface. Their detection limit is about $1 \mathrm{ng} / \mathrm{mL}$ norovirus VLPs in a 40-min assay in a label-free manner. The designed LPFG-based biosensor could be applied in both fast norovirus detection and in vaccine testing [64]. Figure 6 represents experimental setup and process used for modification of fibres to detect noroviruses. 


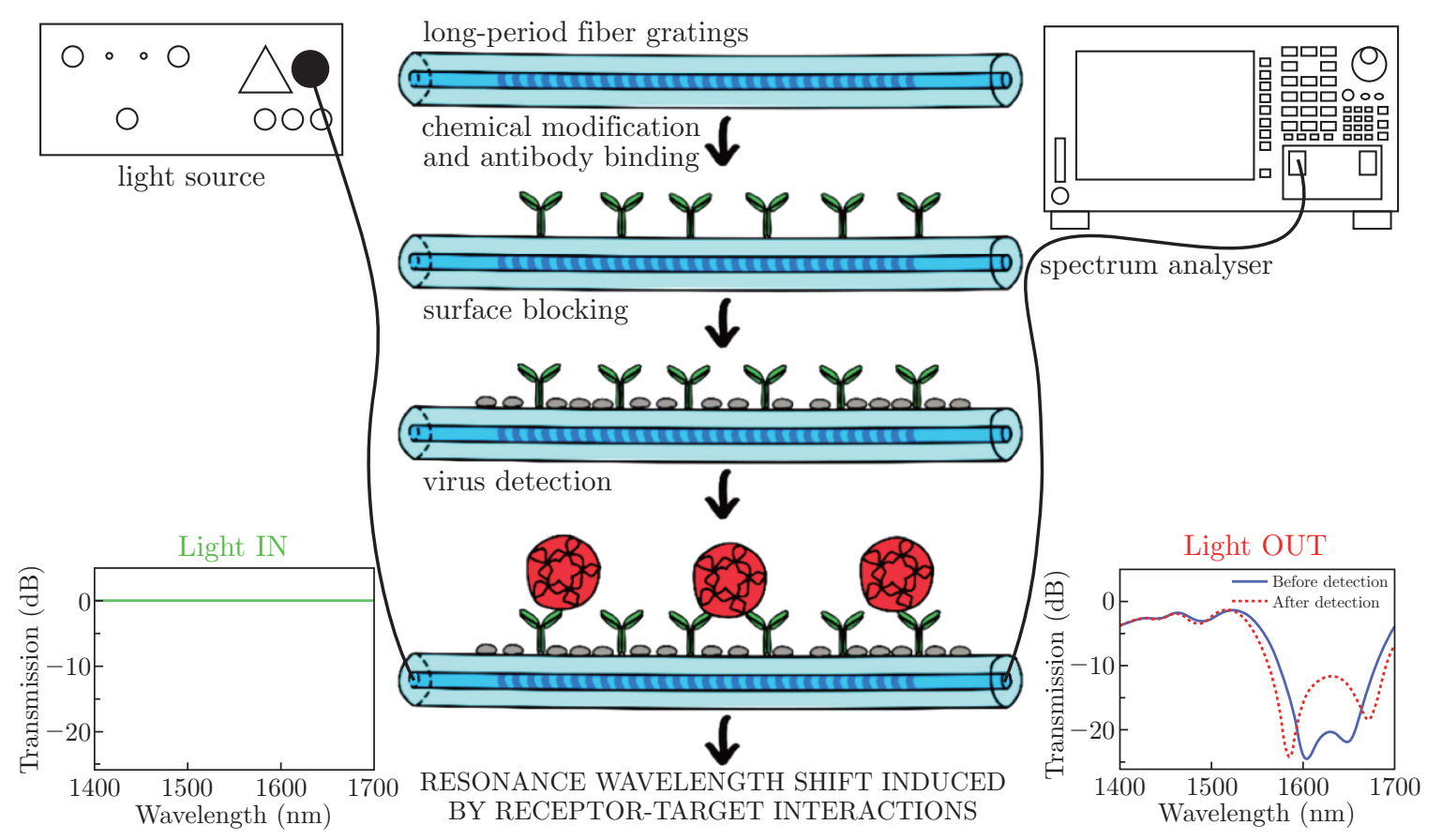

Fig. 6: Schematic representation of the experimental setup and fiber surface modification steps leading to norovirus detection [64]

\subsection{Dengue Virus}

Dengue fever is one of biggest challenge for public health all over the world. About 2.5 billion people are at risk due to this infection, 100 million cases are reported and approximately 25000 people died every year [65]. It belongs to the single-stranded positive-sense RNA viruses of Flavivirus genus and cause diseases related to the visceral and central nervous system in humans. Dengue virus is non apparent infections disease (up to $75 \%$ of infections) or it start from dengue fever to severe illnesses. It range from self-limited, a potentially lethal haemorrhagic and capillary leak syndrome previously termed dengue haemorrhagic fever and dengue shock syndrome [66]. Most widely used rapid method of dengue detection is based on the NS1 glycoprotein tests and ELISA methods in many developed countries.

Zhang et al. reported a biosensor based on the silicon nanowire for dengue serotype 2 detection [67]. Firstly, they attached covalently a nucleic acid peptide chain on the surface of silicon nanowire. Then they obtained a complementary fragment of dengue serotype 2 which was applied on the functionalized silicon nanowire. Before and after binding viruses (dengue serotype 2) they measured the hybridization that show the change in resistance of the silicon nanowire based functionalized biosensor. They also reported that silicon nanowire-based biosensor has the detection limit less than $10 \mathrm{fM}$ concentration. Lim et al. developed a polyvalent phage for the detection of the peptides affinity to NS1 protein [68]. They concluded that in sequence analysis of the peptide, amino acid was basic residue. When NS1 proteins bind then it considerably decreases the current in cyclic voltammetry and enhance the impedance in electrochemical impedance spectroscopy. For NS1 proteins, phage clones were more specific in comparison of BSA (bovine serum albumin) or the M13. Moreover, Deng et al. reported sensing membrane based on anodic aluminium oxide platform for detection of virus [69]. They coated platinum electrodes with the alumina functionalized membrane for the elimination of the solution outside the resistance of nanopores. Then they 
used electrochemical impedance spectroscopy for monitoring the change in impedance within the nanopores with binding of DNA molecule. Finally, they observed a linear increase with increase in response of targeted DNA. D. Wasik et al., reported that SWCNT's have a high surface-tovolume ratio for functionalization with antibody baroreceptor. It enables selective and specific detection of target analytes. SWCNT's allows small perturbations of antibody-analytes binding events to be converted into a measurable electric signal, even at low analyte concentrations. A portable, rapid, and inexpensive diagnostic tools suitable for in-home and point-of-care use [70]. Figure 7 illustrates procedure to functionalise single-walled nanotubes (SWNTs) networks with anti-non-structural protein 1 (NS1) antibodies.

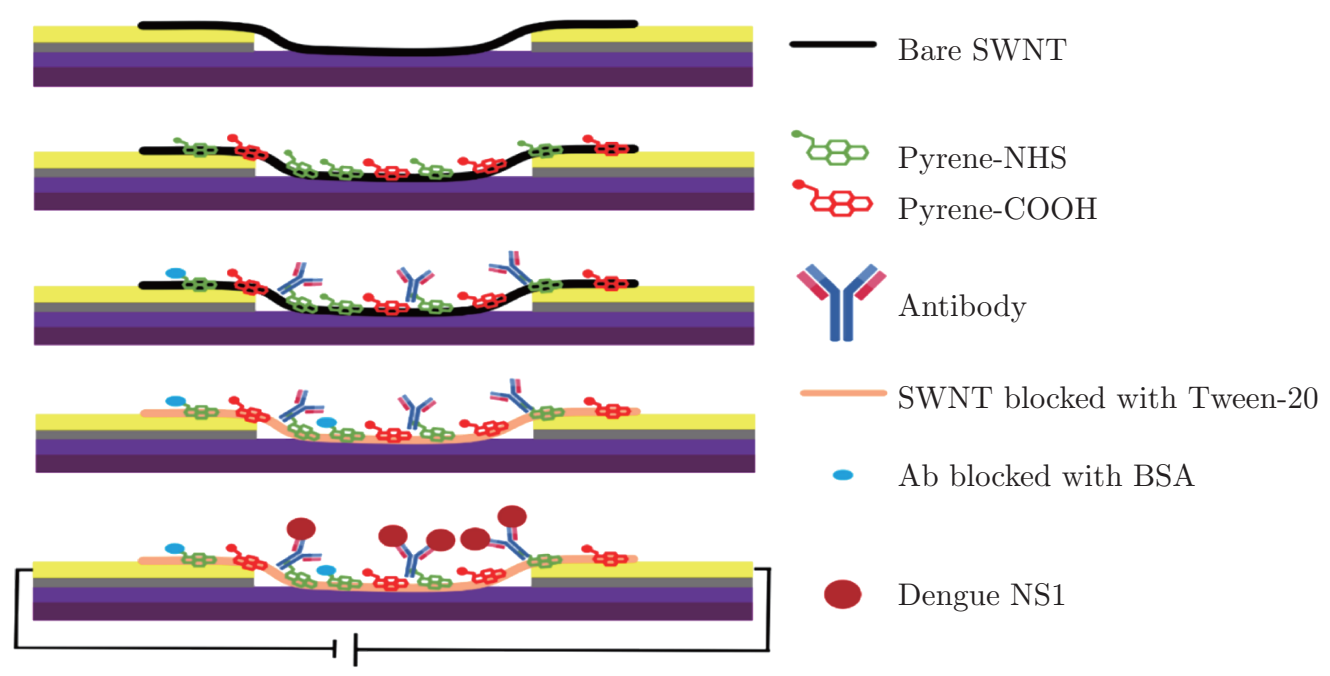

Fig. 7: Schematic of functionalization of single-walled nanotubes (SWNTs) networks with anti-nonstructural protein 1 (NS1) antibody [70]

\subsection{Human Immunodeficiency Virus}

Human immunodeficiency virus (HIV) is a type of lentivirus which is a subset of retroviruses. Lentiviruses are also known as slow viruses because there is time interval between the start of the infection and rise in their symptoms. HIV initiates after entering into the bloodstream that replicate and infects the cells $\left(\mathrm{CD} 4^{+} \mathrm{T}\right)[71]$. As the result, patient suffer from the disease (AIDS) which is one of the most important public health issues. According to the report of WHO, about 35 million people have been suffered from this disease. To detect HIV-1 gene, Babamiri et al. reported an electrochemical luminescence nanosensor. They observed that it has the ability of a sensitive detection within range between $3.0 \mathrm{fm}$ to $0.3 \mathrm{~nm}$. They proved that such nanosensor have an excellent specificity when we compared it with noncomplementary sequences. Lu et al. also prepared a nanosensor to determine HIV-1-related glycoprotein 41 (Gp41). They used synthetic peptides to modify the surface of piezoelectric type nanosensor, which has 579-613 residues of Gp41. They showed that it can selectively bind Gp41 and easily detect through a surface of nanosensor which has an immense affinity to the target their peptides. They calculated the detection limit as $2 \mathrm{ng} / \mathrm{mL}$ [72]. Shafiee et al. reported an optic nanosensor for detection of HIV-1. They mentioned that the targeted virus was adsorbed and influenced a shift with $10 \mathrm{pM}$ resolution. Their detection limit is ranging from $10^{4}$ to $10^{8}$ copies $/ \mathrm{mL}$ [73]. 


\subsection{SARS Coronavirus 2 (COVID-19) Virus}

During the past two decades, three zoonotic coronaviruses have been identified as the cause of large-scale disease outbreaks-Severe Acute Respiratory Syndrome (SARS), Middle East Respiratory Syndrome (MERS), and Swine Acute Diarrhea Syndrome (SADS). SARS and MERS emerged in 2003 and 2012, respectively, and caused a worldwide pandemic that claimed thousands of human lives, while SADS struck the swine industry in 2017. They have common characteristics, such as they are all highly pathogenic to humans or livestock and their agents originated from bats [74].

G. Seo et al. developed a graphene conjugated field-effect transistor (FET) based biosensor for detection of SARS-CoV-2. The biosensor was fabricated by coating specific antibodies on graphene sheets of the FET which help to fight against SARS-CoV-2 spike protein. The samples were taken from swab specimens of COVID-19 patients, antigen proteins and cultured virus and then developed biosensor was used to detect SARS-CoV-2 in these samples. After investigation, results demonstrate that our FET device could detect spike proteins at concentrations of $1 \mathrm{fg} / \mathrm{mL}$ in phosphate buffered saline (PBS) and $100 \mathrm{fg} / \mathrm{mL}$ in clinical transport medium. The developed FET biosensor can also be used to detect SARS-CoV-2 in culture mediums with limit of detection $(1.6 \times 101 \mathrm{pfu} / \mathrm{mL})$ and clinical samples (LOD: $2.42 \times 102$ copies $/ \mathrm{mL})$. It is a simple, rapid and highly responsive immunological biosensing device which require no sample labelling and pretreatment. This technology can also be used to develop biosensors for detection of other new viruses [76]. Figure 8 illustrates graphene conjugated field-effect transistor (FET) based biosensor for detection of SARS-CoV-2 (COVID-19).

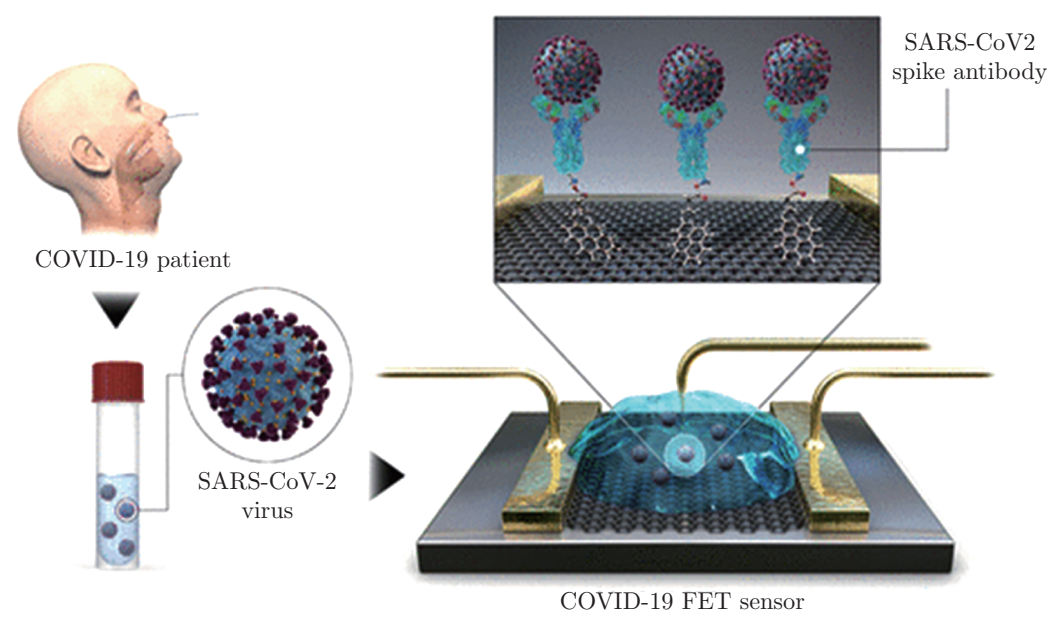

Fig. 8: Schematic representation of SARS-CoV-2 detection using graphene conjugated field-effect transistor (FET) based biosensor [75]

D. Chu et al. developed two different type of PCR assays to identify two different regions (ORF1b and $\mathrm{N}$ ) of the virus genome. These are one step and quantitative real time reversetranscription PCR assays, in which primer and probe sets were designed to determine with SARS coronaviruses. The developed assays were evaluated against respiratory samples from COVID-19 patients and panel of positive and negative controls. The cells infected by coronavirus were used to extract RNA and used as positive control show dynamic range of magnitude. The results of all negative samples were found to be negative and samples from corona patients were found to be positive. The developed assays can be used for early detection of $2019-\mathrm{nCoV}$ in infected people 
due to it fast detection response [75].

\subsection{Other viruses}

J. Jung et al. developed a graphene based immuno-biosensor to detect the rotaviruses. Biosensor was prepared by depositing graphene oxide on amino modified glass surface, then the GO array surface was immobilized by carbodiimide assisted amidation reaction which help to detect rotavirus cells by specific antibody antigen interaction. The AuNP-linked antibodies (Ab-DNAAuNP complexes) were also manufactured and linked with single stranded DNA molecules. The quenching efficiency of graphene oxide was enhanced due to high affinity of amino functional groups of DNA nucleotides for multiple AuNPs. The detection of target cells of pathogens was achieved when Ab-DNA-AuNP complexes were selectively bound to the target cells attached to the GO arrays, which results in decrease of fluorescence emission of graphene oxide by quenching and help in detecting pathogens [77].

Z. Song et al. manufactured a label free method based on graphene oxide for early detection and neutralization of environmental viruses such as EV71 and H9N2. These viruses are generally very stable in environment and less sensitive to organic solvents and detergents. Many viruses also have high risk of transmission within the environment because they are difficult to detect and neutralize. In this work, graphene oxide was used which could easily interact with many viruses and helps in spontaneous extraction of viral RNA to make one step PCR detection possible without any extra procedures in lab. Graphene based nanomaterials can be used to destruct and neutralize the viruses with effectiveness of at-least $6 \log$ loss. So, they can be used to reduce the risk of viral infections by preventing virus transmissions within the environment without any extra cost and time [6].

Y. Yeh et al. manufactured a carbon nanotube size-tunable enrichment microdevice (CNTSTEM) for effective enrichment and concentration of viruses. The microdevice was constructed by aligning and growing nitrogen doped multiwalled carbon nano tubes in the channel sidewall. The inter tubular distance between carbon nano tubes was kept from 17 to $325 \mathrm{~nm}$ according to size of viruses. The manufactured device significantly improves the detection ability and rate of virus isolation by 100 times. An emerging influenza virus strain (avian) was also identified using this microdevice. This novel device and its detection process can be used for early detection of new viruses and provides platform for effectively fighting against viral infectious diseases [78].

\section{Conclusion and Future Perspective}

In the field of clinical virology, smart material based nanosensors are recently developed technology for viral diagnosis and it play an important role in reduction of severe infectious viral diseases. The most important features of these nanosensors are high specificity and sensitivity that matches with other viral diagnostic technique such as serological assays and culture methods. Nevertheless, the technological capabilities alone are inadequate if not sustained by health promotion policies to boost the consciousness and propose the significance of early detection of infectious viral diseases outbreak. In conclusion, good quality diagnosis nanosensor has a cost that only developed countries can afford in regular practice so far, and this is delaying the execution of new-fangled methods in developing world and in disease endemic areas. Conversely, it is anticipated that 
asserted efforts may persist toward developing new high-quality tests inexpensive in low-income countries, which would considerably reinforce disease control strategies.

\section{$5 \quad$ Future Perspective}

- There is need to design user friendly and good quality nanosensors for early detection of viruses.

- Need to develop cost effective smart material based nanosensors for developing countries to diagnose new viruses at early stages.

- Need to manufacture nano-sensing devices which can detect viruses out of the laboratories to save time and avoid spread of disease.

- There is need to develop virus detection mechanism/systems which can be used to detect as well as neutralize effect of viral infections at first point of contact.

- Need to manufacture portable nanosensors which people can use at their places for early detection of infectious diseases.

- Need to develop fast and rapid response nanosensors linked with our daily use smart devices.

- Need to develop wearable and flexible nanosensors devices which can be used for quick viral detections especially in areas exposed to infectious diseases.

- There is need to spend more funds in research sector for poor countries which are more vulnerable to the spread of epidemics.

\section{Acknowledgment}

We would like to thank the support of the EU Horizon 2020 and University of Manchester through projects with project codes 644268 - ETEXWELD - H2020-MSCA-RISE-2014, AA14512 (UMRI project "Graphene-Smart Textiles E-Healthcare Network") and R119938 ('Protective Efficiency of Respiratory Protective Equipment (RPE) against Byssinosis for Cotton Workers').

\section{References}

[1] Saylan Y, Denizli A. Virus detection using nanosensors. Nanosensors for Smart Cities: 2020; 501511.

[2] Alvarez MM, Aizenberg J, Analoui M, et al. Emerging Trends in Micro- and Nanoscale Technologies in Medicine: From Basic Discoveries to Translation. ACS Nano: 2017; 11: 5195-5214.

[3] Malik AA, Nantasenamat C, Piacham T, Molecularly imprinted polymer for human viral pathogen detection. Mater. Sci. Eng. C: 2017; 77: 1341-1348.

[4] Hotez PG, Blue marble health and "the big three diseases": HIV/AIDS, tuberculosis, and malaria, Microbes Infect. 2015; 17: 539-541.

[5] Chan YK, Gack MU, Viral evasion of intracellular DNA and RNA sensing. Nat. Rev. Microbiol: 2016; 14: 360-373.

[6] Song Z, Wang X, Zhu G, et al. Virus capture and destruction by label-free graphene oxide for detection and disinfection applications. Small: 2015; 11: 1771-1776. 
[7] Hashem IAT, Chang V, Anuar NB, et al. The role of big data in smart city. Int. J. Inf. Manage: 2016; 36: 748-758.

[8] Alvear O, Calafate CT, Cano JC, et al. Crowdsensing in smart cities: Overview, platforms, and environment sensing issues. Sensors: 2018; 18: 1-28.

[9] Zhang GA, Gu JY, Bao ZH, et al. Joint routing and channel assignment algorithms in cognitive wireless mesh networks. Trans. Emerg. Telecommun. Technol: 2014; 25: 294-307.

[10] Goode JA, Rushworth JVH, Millner PA, Biosensor Regeneration: A Review of Common Techniques and Outcomes. Langmuir: 2015; 31: 6267-6276.

[11] Verma N, Bhardwaj A. Biosensor Technology for Pesticides-A review. Appl. Biochem. Biotechnol: 2015; 175: 3093-3119.

[12] Saylan YF, Yilmaz E, Özgür A, et al. Molecular imprinting of macromolecules for sensor applications. Sensors: 2017; 17: 898.

[13] Cho KH, Shin DH, Oh J, et al. Multidimensional Conductive Nanofilm-Based Flexible Aptasensor for Ultrasensitive and Selective HBsAg Detection. ACS Appl. Mater. Interfaces: 2018; 10: 2841228419.

[14] Luigi LS, Lucio V. Electromagnetic Nanoparticles for Sensing and Medical Diagnostic Applications. Materials: 2018; 11(4): 1-21.

[15] Osman B, Uzun L, Beşirli N, et al. Microcontact imprinted surface plasmon resonance sensor for myoglobin detection. Mater. Sci. Eng. C.: 2013; 33: 3609-3614.

[16] Saylan Y, Yllmaz F, Derazshamshir A, et al. Synthesis of hydrophobic nanoparticles for real-time lysozyme detection using surface plasmon resonance sensor. J. Mol. Recognit.: 2017; 30: 1-7.

[17] Wang Z, Wang X, Li M, Y. Gao, et al. Highly Sensitive Flexible Magnetic Sensor Based on Anisotropic Magnetoresistance Effect. Adv. Mater.: 2016; 28: 9370-9377.

[18] Battal D, Akgönüllü S, Yalcin MS, et al. Molecularly imprinted polymer based quartz crystal microbalance sensor system for sensitive and label-free detection of synthetic cannabinoids in urine. Biosens. Bioelectron.: 2018; 111: 10-17.

[19] Cheng S, Hideshima S, Kuroiwa S, et al. Label-free detection of tumor markers using field effect transistor (FET)-based biosensors for lung cancer diagnosis. Sensors Actuators, B Chem.: 2015; 212: 329-334.

[20] Anik Ü, Tepeli Y, Diouani MF. Fabrication of Electrochemical Model Influenza A Virus Biosensor Based on the Measurements of Neuroaminidase Enzyme Activity. Anal. Chem.: 2016; 88: 61516153.

[21] Lv M, Liu Y, Geng J, et al. Engineering nanomaterials-based biosensors for food safety detection. Biosens. Bioelectron: 2018; 106: 122-128.

[22] Saylan Y, Denizli A. Molecular fingerprints of hemoglobin on a nanofilm chip. Sensors: 2018; 18(9): 3016.

[23] Saylan Y, Erdem Ö, Ünal S, et al. An alternative medical diagnosis method: Biosensors for virus detection, Biosensors. 2019; 9(2): 65.

[24] Saylan Y, Erdem Ö, Cihangir N, et al. Detecting Fingerprints of Waterborne Bacteria on a Sensor. Chemosensors: 2019; 7: 33 .

[25] Safran V, Göktürk, A. Derazshamshir, F. et al. Rapid sensing of $\mathrm{Cu}+2$ in water and biological samples by sensitive molecularly imprinted based plasmonic biosensor. Microchem. J.: 2019; 148: 141-150.

[26] Ramanathan K, Danielsson B. Principles and applications of thermal biosensors. Biosens. Bioelectron.: 2001; 16(6): 417-423. 
[27] Byrne B, Stack E, Gilmartin N, et al. Antibody-Based Sensors: Principles, Problems and Potential for Detection of Pathogens and Associated Toxins. Sensors: 2009; 9(6): 4407-4445.

[28] Sridhar S, To KKW, Chan JFW, et al. A Systematic Approach to Novel Virus Discovery in Emerging Infectious Disease Outbreaks. J. Mol. Diagnostics.: 2015; 17(3): 230-241.

[29] Usa Thisyakorn and Chule Thisyakorn, Adult Dengue: 2015; 46(4): 47-56.

[30] Diel DG, Lawson S, Okda F, et al. Porcine epidemic diarrhea virus: An overview of current virological and serological diagnostic methods, Virus Res.: 2016; 226: 60-70.

[31] Balasuriya UBR, Crossley BM, Timoney PJ. A review of traditional and contemporary assays for direct and indirect detection of Equid herpesvirus 1 in clinical samples. J. Vet. Diagnostic Investig.: 2015; 27 : 673-687.

[32] Chang JE, Lee DS, Ban SW, et al. Analysis of volatile organic compounds in exhaled breath for lung cancer diagnosis using a sensor system, Sensors Actuators. B Chem.: 2018; 255, 800-807.

[33] Seeger C, Mason WS. Molecular biology of hepatitis B virus infection. Virology: 2015; 479-480, 672-686.

[34] Sureau C. Hepatitis Delta Virus: Virology and Replication: 2016.

[35] Hassen WM, Chaix C, Abdelghani A, et al. An impedimetric DNA sensor based on functionalized magnetic nanoparticles for HIV and HBV detection. S Sensors Actuators, B Chem.: 2008; 134(2): 755-760.

[36] Uzun L, Say R, Ünal S, et al. Production of surface plasmon resonance based assay kit for hepatitis diagnosis. Biosens. Bioelectron.: 2009; 24(9): 2878-2884.

[37] Chowdhury AD, Takemura K, Li TC, et al. Electrical pulse-induced electrochemical biosensor for hepatitis E virus detection, Nat. Commun.: 2019; 10: 4-7.

[38] Cheng Z, Yiping C, Xinmiao L, et al. Detection of Hepatitis B Virus M204I Mutation by Quantum Dot-Labeled DNA Probe. Sensors (Basel, Switzerland): 2017; 17(5): 1-9.

[39] Tasoglu S, Cumhur TH, Inci F, et al. Advances in Nanotechnology and Microfluidics for Human Papillomavirus Diagnostics. Proc. IEEE.: 2015; 103(2): 161-178.

[40] Inan H, Wang S, Inci F, et al. Isolation, Detection, and Quantification of Cancer Biomarkers in HPV-Associated Malignancies. Sci. Rep.: 2017; 7: 1-11.

[41] Teengam P, Siangproh W, Tuantranont A, et al. Multiplex Paper-Based Colorimetric DNA Sensor Using Pyrrolidinyl Peptide Nucleic Acid-Induced AgNPs Aggregation for Detecting MERS-CoV, MTB, and HPV Oligonucleotides. Anal. Chem.: 2017; 89: 5428-5435.

[42] Peng X, Zhang D, Lu Y, et al. Ultrathin Ti3C2 nanosheets based "off-on" fluorescent nanoprobe for rapid and sensitive detection of HPV infection. Sensors Actuators, B Chem.: 2019; 286: 222-229.

[43] Kreil TR. Treatment of Ebola Virus Infection with Antibodies from Reconvalescent Donors. Emerg. Infect. Dis.: 2015; 21(3): 521-523.

[44] Baca JT, Severns V, Lovato D, et al. Rapid detection of Ebola virus with a reagent-free, point-ofcare biosensor. Sensors: 2015; 15: 8605-8614.

[45] Natesan M, Wu SW, Chen CI, et al. A Smartphone-Based Rapid Telemonitoring System for Ebola and Marburg Disease Surveillance. ACS Sensors: 2019; 4: 61-68.

[46] Yanik AA, Huang M, Kamohara O, et al. An Optofluidic Nanoplasmonic Biosensor for Direct Detection of Live Viruses from Biological Media. Nano Lett.: 2010; 10(12): 4962-4969.

[47] Y. Chen, R. Ren, H. Pu, X. Guo, J. Chang, G. Zhou, S. Mao, M. Kron, J. Chen, Field-Effect Transistor Biosensor for Rapid Detection of Ebola Antigen, Sci. Rep. 7 (2017) 4-11.

[48] Hennessey M, Fischer M, Staples JE. Zika Virus Spreads to New Areas - Region of the Americas, May 2015-January 2016. Am. J. Transplant.: 2016, 16(3): 1031-1034. 
[49] Meagher RJ, Negrete OA, Van Rompay KK. Engineering Paper-Based Sensors for Zika Virus. Trends Mol. Med.: 2016; 22: 529-530.

[50] Afsahi S, Lerner MB, Goldstein JM, et al. Novel graphene-based biosensor for early detection of Zika virus infection. Biosens. Bioelectron.: 2018; 100: 85-88.

[51] Ajeet K, Adriana Y, Sanjeev K, et al. A sensitive electrochemical immunosensor for label-free detection of Zika-virus protein. Sci. Rep.: 2018; 8: 3-7.

[52] Song J, Mauk MG, Hackett BA, et al. Instrument-Free Point-of-Care Molecular Detection of Zika Virus. Anal. Chem.: 2016; 88(14): 7289-7294.

[53] Moulick A, Richtera L, Milosavljevic V, et al. Advanced nanotechnologies in avian influenza: Current status and future trends - A review. Anal. Chim. Acta: 2017; 983: 42-53.

[54] Tam PD, Hieu NV, Chien N D, et al. DNA sensor development based on multi-wall carbon nanotubes for label-free influenza virus (type A) detection. J. Immunol. Methods.: 2009; 350(1-2): 118-124.

[55] Vollmer F, Arnold S, Keng D. Single virus detection from the reactive shift of a whispering-gallery mode[J]. Proc. Natl. Acad. Sci.: 2009; 105(52): 20701-20704.

[56] Bai H, Wang R, Hargis B, et al. A SPR Aptasensor for Detection of Avian Influenza Virus H5N1. Sensors: 2012; 12(9): 12506-12518.

[57] Su D, Wu K, Krishna VD, et al. Detection of influenza A virus in swine nasal swab samples with a wash-free magnetic bioassay and a handheld giant magnetoresistance sensing system. Front. Microbiol.: 2019; 10: 1-10.

[58] Siuzdak K, Niedziakowski P, Sobaszek M, et al. Biomolecular influenza virus detection based on the electrochemical impedance spectroscopy using the nanocrystalline boron-doped diamond electrodes with covalently bound antibodies.Sensors Actuators, B Chem.: 2019; 280: 263-271.

[59] Joshi SR, Sharma A, Kim GH, et al. Low cost synthesis of reduced graphene oxide using biopolymer for influenza virus sensor. Mater. Sci. Eng. C.: 2020; 108: 110465.

[60] Hai W, Goda T, Takeuchi H, et al. Specific Recognition of Human Influenza Virus with PEDOT Bearing Sialic Acid-Terminated Trisaccharides. ACS Appl. Mater. Interfaces.: 2017; 9(16): 14162.

[61] Robilotti E, Deresinski S, Pinsky BA, Norovirus. Clin. Microbiol. Rev.: 2015; 28: 134-164.

[62] Ashiba H, Sugiyama Y, Wang X, et al. Detection of norovirus virus-like particles using a surface plasmon resonance-assisted fluoroimmunosensor optimized for quantum dot fluorescent labels. Biosens. Bioelectron.: 2017; 93: 260-266.

[63] Marieke B, Wences A, Alejandra E, et al. Incidence and clinical profile of norovirus disease in Guatemala, 2008-2013. Clin. Infect. Dis.: 2018; 67: 430-436.

[64] Singh B, Ganguly A, Sunwoo HH. Current and Future Diagnostic Tests for Ebola Virus Disease. J. Pharm. Pharm. Sci.: 2016, 19(4): 530-551.

[65] Mustafa MS, Rasotgi V, Jain S, et al. Discovery of fifth serotype of dengue virus (DENV-5): A new public health dilemma in dengue control. Med. J. Armed Forces India: 2015; 71: 67-70.

[66] Diamond MS, Pierson TC. Molecular Insight into Dengue Virus Pathogenesis and Its Implications for Disease Control. Cell: 2015; 162(3): 488-492.

[67] Zhang GJ, Zhang L, Huang MJ, et al. Silicon nanowire biosensor for highly sensitive and rapid detection of Dengue virus, Sensors Actuators. B Chem.: 2010; 146: 138-144.

[68] Lim JM, Kim JH, Ryu MY, et al. An electrochemical peptide sensor for detection of dengue fever biomarker NS1. Anal. Chim. Acta.: 2018; 1026: 109-116.

[69] Liu Y, Hou C, Jiao T, et al. Self-assembled AgNP-containing nanocomposites constructed by electrospinning as efficient dye photocatalyst materials for wastewater treatment. Nanomaterials: $2018 ; 8(1): 35$. 
[70] Wasik D, Mulchandani A, Yates M. Salivary Detection of Dengue Virus NS1 Protein with a LabelFree Immunosensor for Early Dengue Diagnosis. Sensors: 2018; 18: 2641.

[71] Inci F, Tokel O, Wang S, et al. Nanoplasmonic quantitative detection of intact viruses from unprocessed whole blood, ACS Nano.: 2013; 7: 4733-4745.

[72] Lu CH, Zhang Y, Tang SF, et al. Sensing HIV related protein using epitope imprinted hydrophilic polymer coated quartz crystal microbalance. Biosens. Bioelectron: 2012; 31: 439-444.

[73] Shafiee H, Lidstone EA, Jahangir M, et al. Nanostructured optical photonic crystal biosensor for HIV viral load measurement. Sci. Rep.: 2014; 4: 1-7.

[74] Fan Y, Zhao K, Shi ZL, et al. Bat coronaviruses in China. Viruses: 2019; 11: 27-32.

[75] Chu DKW, Pan Y, Cheng SMS, et al. Molecular Diagnosis of a Novel Coronavirus (2019-nCoV) Causing an Outbreak of Pneumonia. Clin. Chem.: 2020; 7: 1-7.

[76] Seo G, Lee G, Kim MJ, et al. Rapid Detection of COVID-19 Causative Virus (SARS-CoV-2) in Human Nasopharyngeal Swab Specimens Using Field-Effect Transistor-Based Biosensor, ACS Nano: 2020.

[77] Jung JH, Cheon DS, Liu F, et al. A graphene oxide based immuno-biosensor for pathogen detection. Angew. Chemie - Int. Ed.: 2010; 49: 5708-5711.

[78] Yeh YT, Tang Y, Sebastian A, et al. Tunable and label-free virus enrichment for ultrasensitive virus detection using carbon nanotube arrays. Sci. Adv.: 2016; 2: 1-13. 